\title{
流水地貌实验的发展与创新 缅怀沈玉昌先生创建流水地貌实验室的历程
}

\author{
金德生,乔云峰” \\ (中国科学院陆地水循环与地表过程重点实验室, 中国科学院地理科学与资源研究所, 北京 100101)
}

\begin{abstract}
摘 要: 作为中国现代河流地貌研究的开拓者和奠基人,沈玉昌先生对开创流水地貌实验研究的初衷, 为后人创新 流水地貌实验开拓了先河, 特撰写本文纪念先生 100 周年诞辰。主要内容有: (1)憧憬河流地貌实验与筹建流水地 貌实验室。包括先生的初衷、实验室调研与筹建、实验试运行及起步实验; 2 流水地貌实验室扩建及实验研究蓬勃 发展。包括结合国家重大及地方委托项目开展的一系列实验研究, 开拓流域地貌系统及坡面发育演变的实验, 建 立河流地貌过程响应实验相似型理论; (3)河流地貌实验的新进展。包括河流地貌实验室建设及实验装置更新, 河 型系统发育演变过程实验的新进展, 穹隆与㘬陷非均匀升降对河流地貌系统发育影响的实验等。最后进行了展 望, 为了使中国实验流水地貌学研究继续深化, 需要进行 6 个方面创新探索, 特别是: 加强构造运动、气候变化及人 类活动快速变化导致的非稳定状态河流动力地貌过程实验研究, 揭示其复杂性、敏感性及前兆性特征, 加强实验研 究力量的协作与融合,加强流水地貌实验研究的综合性、交叉性学术交流。
\end{abstract}

关 键 词: 缅怀初衷; 河流地貌; 实验; 创新发展

1 引言

20 世纪 60 年代, 中国河流研究的两位著名学 者——河流地貌学带头人沈玉昌先生和河流泥沙 运动力学与河流动力学带头人钱宁先生, 携手共 进, 驱使河流地貌学与河流动力学两大学科互相融 合, 开拓了研究河流地貌的新方向。沈先生在推崇 开拓中国现代地理科学的基础上, 对开创现代河流 地貌学以及地貌学多个方面的研究, 也作出了杰出 的贡献。

在纪念沈玉昌先生 100 周年诞辰之际, 乘此机 会, 我们深切缅怀先生对河流地貌实验研究给予的 厚望, 回顾 50 多年来中国河流地貌研究的进展, 以 便探索流水地貌实验的新征程。
2 为深化河流地貌研究而筹建流水地 貌实验室

\section{1 沈先生的河流地貌实验初衰}

提起河流地貌的实验研究,还得追溯到 20 世纪 60 年代初。中国河流地貌学研究对象, 正由流域地 貌与河谷地貌转向河床地貌的发育演变。在此之 前, 20 世纪 40-50 年代美国以及前苏联早已开展了 河流地貌的实验, 且有一定深度, 河流地貌学由定 性向定量研究发展, 并由野外调查研究向室内外实 验研究相结合发展。1947年, 前苏联科学院地理研 究所的地貌实验室进行大型流水形态发育过程研 究(Великанов, 1950); 1945 年, 在美国陆军工程兵 团维克斯堡实验室中成功进行了曲流造床实验

收稿日期:2016-10; 修订日期: 2016-11。

基金项目: 国家自然科学基金学部主任基金项目(41340021) [Foundation: Project of Division Director of National Natural Science Foundation of China, No.41340021]。

作者简介: 金德生(1940), 男, 研究员, 长期从事流水地貌及实验流水地貌研究,E-mail: jinds @igsnrr.ac.cn。

通讯作者:乔云峰(1974), 男, 博士, 高级工程师, 主要从事水文水资源及实验研究, E-mail: qiaoyf@igsnrr.ac.cn。

引用格式: 金德生, 乔云峰. 2016. 流水地貌实验的发展与创新: 缅怀沈玉昌先生创建流水地貌实验室的历程[J]. 地理科学进展, 35(11): 14201430. [Jin D S, Qiao Y F. 2016. Development and innovation of fluvial geomorphological experiments: To mark contributions of Professor Shen Yuchang on the hundredth anniversary of his birth[J]. Progress in Geography, 35(11): 1420- 1430.]. DOI: 10.18306/ dlkxjz.2016.11.012 
(Friedkin, 1945); 1950s, 罗辛斯基等(1956)在分析河 床成因的基础上, 进行了有关实验研究。莫斯科大 学地理系露天地貌实验室运用提拉式控制的构造 升降装置, 并借助陆地摄影仪拍摄照片, 进行了一 系列有关内外营力对河流发育演变影响的大型实 验(马卡维耶夫等, 1966)。在国际上取得很大进展 的同时, 国内水利泥沙界对河型成因的实验研究也 已初见端睨(李保如, 1963; 唐日长等, 1964; 尹学 良, 1965)。

忆往昔, 沈玉昌先生在进行长江上游三峡河谷 地貌调查研究时, 发现长江三峡河段基岩河床的深 槽中存在不少深潭, 有些深潭底部的海拔高程, 竟 然比海平面还低(沈玉昌, 1965), 但这种河床地貌形 态如何形成发育令他不得其解。经了解, 他得知国 外兴起的流水地貌实验手段在模拟河流地貌的发 育演变过程的同时, 还能研究內营力对河流发育演 变影响。受此启示, 热衷于河流地貌研究现代化、 实验化的沈先生, 便开始热切关心流水地貌的实验 研究, 想通过室内实验来研究这一类河流地貌的成 因问题, 提高地貌研究的科学化、实验化水平。他 认为, 河流地貌的实验研究要有自己的特色, 通过 模拟实验研究, 不仅要研究外营力对河流发育的影 响, 同时希望研究内、外营力同时对河流发育的影 响, 但不必搞水利泥沙界那样的中大比尺模型实 验。沈先生设想在室内水槽中挖一条小河道, 用水 流冲刷, 研究水沙对河道发育演变的影响。他将设 想征求水科院河渠所钱宁先生的意见。钱先生建 议, 筹建一个像样的室内流水地貌实验室, 规范地 进行模拟实验。这一设想和建议, 得到时任中国科 学院地理所党委李秉枢书记、黄秉维所长的支持, 科研处长黄坚也给予积极配合。1961 年, 在沈玉昌 领导下, 地貌室开始筹建流水地貌实验室, 由陆中 臣负责具体的筹建工作。实验室主要包括河流地 貌实验与坡地地貌实验两大部分。

\section{2 河流地貌实验室调研、设计及筹建(1962-}

\section{5 年)}

1962 年, 陆中臣受地貌室委托, 邀请刚从原苏 联莫斯科大学地理系学成回国的龚国元到地理所 工作; 地貌室任命龚国元为河流地貌实验室筹建组 负责人, 成员有陆中臣、洪笑天、郭庆伍等。筹建组 在室主任沈玉昌先生统一领导下开展工作。

着手选派人员前往中国水科院河渠研究所进
修、组织国内外情况调研、翻译有关信息资料、制定 规划设计方案以及联系设备加工等。早已被选派 前往中国水科院河渠研究所进修的陆中臣、郭庆伍 继续学习河床演变、泥沙运动、模型试验理论及方 法; 组织筷静娟、陆中臣、杨毅芬、杜端秉等翻译马 卡维耶夫等(1961)的《实验地貌学》, 由龚国元、沈玉 昌、经纬等审校, 于 1966 年由科学出版社出版, 作为 河流地貌实验理论与方法的借鉴。同时由陆中臣 负责调研国际上前苏联及欧、美、日等国家 109个实 验室的情况, 按实验室的宽度与长度比例、场地条 件、实验要求、确定实验室的规模, 并特地设计地壳 运动升降装置, 洪笑天设计了附有摄影测架的手控 电动测桥及有关设备, 由郭庆伍主要配合联系设备 加工、仪器购置、摄影及实验操作训练。实验设备 的主要部件如手控电动测桥、千斤顶及调坡轨道由 中国科学院力学研究所加工制造, 8 个液压千斤顶 电动调控的地壳构造运动升降装置由阜新液压件 厂加工制造。1963 年开始, 建设泵房、供水设备、实 验主槽、稳流槽、沉沙池以及回水暗道等。同时逐 步配套有关河床地形、水沙测试仪器、沙样分析及 凌空摄影设备等。实验室初步于 1965 年建成, 1967 年初地壳构造运动升降装置最后安装调试完成。

这是 20 世纪 60 年代国内独一无二的地貌实验 室, 具有世界上最先进、一流的地壳构造运动升降 装置, 直到现在国外尚未见更先进的同类装置, 这 是非常引以自豪的。

\section{3 河流地貌实验室试运行 (1969-1977 年)}

实验室初步建成后, 由于文革干扰, 实验室成 员东流西散, 加之极左思潮的影响, 无法正常开展 实验研究, 军代表甚至企图将其改造成电影放映 厅,差点厄运降临。

1969年, 在“抓革命、促生产”指示的影响下, 受 黄河水利委员会委托,作为黄河河口整治规划的延 续和实施, 实验室与黄河水利委员会、山东省水利 科学研究所及山东省黄河垦利修防段等单位合作, 进行了 “黄河口十八户引黄放淤模型试验”, 取得了 满意结果。该模型试验是实验室建成后结合水沙 调试的首次实验。

1972 年, 按照“科研要广泛结合生产实践的基 础上往高里提” 的思想, 在沈玉昌先生直接领导下, 积极开展长江中下游河型与河道演变调查研究, 对 2 个地处安徽境内, 富有代表性的分汉河段进行重 
点剖析。其中一个是顺直分汉河型的马鞍山河段, 另一个是鹅头状分汉河型的官州河段。1973年, 进 行节点对分汉河道演变影响的自然模型实验, 结果 与长江中下游分汉河型形成的实际情形基本一致 (罗海超等, 1980);1973-1974 年, 受马鞍山钢铁公司 委托, 完成了“长江下游马鞍山河段 31 \#葲房淤积与 整治模型实验” (中国科学院地理研究所地貌研究 室, 1978);1975-1977, 受安徽省长江修防处及安庆 修防段委托, 共同进行了“长江下游官洲河段演变 趋势与整治的定床与局部动床模型实验(中国科学 院地理所地貌室, 1981)。

该时期流水地貌实验室尚处于试运行阶段,在 野外深人细致踏勘调查, 内业充分阅读深人分析历 史地图、文献资料、地质钻探、航空遥感、水文泥沙 测验资料的基础上,结合生产实践的需求实行室内 模拟试验研究。提供了《长江下游官洲河道整治定 床模型试验报告》《长江下游官洲河道整治动床试 验报告》等, 为河道整治提出了治理方案。实验室 一开始就结合生产需要, 使实验试运行有了良好的 开端, 结合河道治理及整治工程的需求, 进行必要 的自然模型与小比尺模型实验, 注重河道演变趋势 分析。

\section{4 河流地貌实验初始起步 (1978-1984 年)}

随着 1976年文化大革命的结束与科学的春天 到来, 实验室开始新的起步。流水地貌实验处在起 步阶段时,一方面继续结合生产需要, 开始探求分 汊河道的成因演变; 另一方面着力开始人才培养与 教育。

1978 年, 受长江流域规划办公室委托, 协同长 江航道局规划设计研究所, 在完成长江中下游城陵 矶一河口段河道成因演变调查的基础上,进行“长 江中下游分汉河道成因与演变趋势的自然模型实 验”(金德生等, 1985)。实验表明, 分汉河型成因与 演变主要受地壳构造运动、来水来沙条件、及边界 条件影响; 节点控制江心洲发育, 河漫滩结构物质 组成及水沙特性, 影响分汉河道的形成与演变; 获 得了发育弯曲与分汉河型的临界河漫滩结构组成, 当二元相结构中河漫滩相与河床相组成之比大于 $50 \%$ 时, 有利于发育弯曲河型, 否则有利于发育分 汉河型。但是, 没有节点控制时, 双曲波水流在冲 积物中同样可以形成江心洲。同时复演了江心洲 的发育及演变过程发现, 全新世早期古长江较稳
定、演变较慢, 达到平衡和最小消能率的时间较长; 中期古长江则相反。随机过程分析表明,影响河型 发育各要素与效能率间具有协调一致性,可用空间 结构模式描述。1982 年,洪笑天等(1987)完成了弯 曲河道形成发育的自然模型试验。

与此同时, 沈先生着力培养人才。1979年, 蔡 强国进行了地壳构造运动对河型转化影响的自然 模型实验, 撰写硕士论文《地壳构造运动对河型转 化影响的实验研究》(蔡强国, 1982);1980年, 完成了 边界条件对河床演变影响的自然模型实验,许昫心 结合撰写硕士论文《边界条件对水库下游河床演变 的影响》(许昫心, 1983); 1981年, 为了培养流水地貌 实验研究人才, 选送笔者赴美国科罗拉多州立大学 地球资源系, 在合作导师 S.A.Schumm 指导下, 进修 实验流水地貌学, 1984年8月学成回国。

该时期,完成了不少实验,但是模型实验的理 论与方法基本上习惯用来分析河道演变趋势的自 然模型及小比尺模型方法, 尚未突破, 开发出更适 合于地学自身特点的模型实验理论与实验方法。

\section{3 流水地貌实验室扩建及实验研究蓬 勃发展(1985-2000年)}

1985-1994年, 因体制改革开放的需求, 河流地 貌实验室更名为流水地貌实验室; 1994-2000年,实 验室更名为河流与海岸地貌实验室。

1985 年, 实验室扩建, 拥有面积分别为 $450 \mathrm{~m}^{2}$ 及 $600 \mathrm{~m}^{2}$ 的河流地貌模拟实验厅及流域地貌模拟 实验厅各 1 座, 具有 2 个实验水槽, 1 套人工降雨装 置、2套供水加沙设备、1 个多功测桥系统、凌空及测 架式摄影装置各 1 套、多台测验仪器及沉积物分析 设备; 在野外建有小流域径流、泥沙综合观测试验 场。其宗旨依然是研究流水地貌过程及定量化, 弥 补野外考察和定位观测的不足,提高地貌学理论及 研究技术水平,为国民经济建设第一线服务。20世 纪 80 年代中期开始, 以流域系统为重点, 点面结合, 运用过程响应模型与小比尺模型进行实验,包括： 流域地貌发育与坡面侵蚀过程实验、河道演变及复 杂动力过程实验、河口及陆海交接带地貌过程实 验, 以及数字流水地貌过程及模拟研究。这一时期 取得一系列研究成果, 室内、外实验的理论与方法 技术也取得许多进展。 


\section{1 结合国家重大及地方委托项目开展一系列实验} 研究

1985 年以来, 实验室先后承担国家重大任务、 地方委托任务与国家自然科学基金项目等 15 项。

1985-1986 年, 完成三峡工程前期重大科研项 目“三峡工程对生态与环境影响”课题专题“长江三 峡水利枢纽修建后对下游河道变化影响的模拟实 验”。实验表明: 在建库的前几年, 上荆江全河段平 均弯曲半径增大, 建库 10 年后, 弯曲半径的均值与 建库前相当,但上段曲率由小变大再变小, 中段介 乎中间,下段具有变小趋势; 除近库段局部出现分 汉趋势外, 河道保持弯曲, 局部河段发生切滩现 象。在三峡建库后, 下荆江的弯曲率与波长波幅比 间保持良好的反比关系, 所不同的是在同样弯曲情 况下,上荆江的波长波幅比略大; 下荆江的河道比 降小于上荆江, 实验验证了分析的结论(尤联元等, 1987)。1985-1987 年, 再次受安徽省马鞍山市长江 修防处委托, 进行“长江马鞍山河道演变趋势模型 试验研究” 相关工作。以野外调研及室内模型实验 为基础, 结合实测水文泥沙资料、河岸和河床组成 物质, 以及历史资料的分析, 查明长江马鞍山河段 各支汉道深槽、边滩突发交替及崩岸点突发上提的 周期演变规律, 分析河道演变趋势并提出了整治方 案; 完成了《长江下游马鞍山河段演变过程响应模 型试验报告》《马鞍山河道演变趋势定床比尺模型 试验报告》《马鞍山河道演变趋势局部动床模型试 验》及《马鞍山河道演变趋势模型试验总结报告》等 4 份报告(金德生等, 1985; 金德生等, 1991)。同时, 完成马鞍山钢铁公司及长江马鞍山河道修防处联

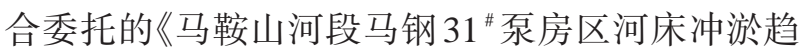
势及整治模型实验研究》。实验指出: 泵房区河床 冲淤具有周期性规律, 周期大约 20 年, 提出了何家 洲串沟局部疏导及泵房区枯水期仍需挖泥等整治 方案。此外, 还完成了“马鞍山河段马钢自备热电 站区河床冲淤趋势及修建码头可行性研究”(金德 生等, 1992)。

值得指出的是, 1992-1995 年, 实验室完成了由 水利部、中国科学院和地质矿产部共同组织的“八 五”国家重点科技攻关项目 “黄河治理与水资源开 发利用” “黄河流域灾害环境演变趋势及治理对策” 课题(85-926-07)第二专题; 子专题《环境因素变化 与下游地上河的发展》(07-02-01), 流水地貌实验室
承担了黄河下游地上河发展趋势和环境后效研究 (金德生, 1997)。1996-1998年完成了黄河水利委员 会勘测设计院委托项目“小浪底水库下游河床调整 及河型转化的地貌研究”。该项目工作十分复杂, 涉及多学科、多变量和多约束条件, 力求运用多学 科方法进行综合研究, 以便择优小浪底水库的运用 方式。经过两年多时间,完成研究任务, 编写了相 关的研究报告及补充研究报告, 为合理选择小浪底 水库运用方式提供依据(金德生, 张欧阳等 2000)。

1997-1998 年,完成了国家自然科学基金委员 会和中国长江三峡工程开发总公司联合资助的国 家自然科学基金重大项目(No.5949360)“三峡水利 枢纽建成后下游河势河型研究” 的“荆江河型河势 变化实验研究”课题中的子课题“江湖流量关系变 异对长江中游河道演变趋势影响的实验研究”, 探 讨荆江与洞庭湖流量变化及相应含沙量改变后, 对 其下游城陵矶一汉口段分汉河型冲淤变化的影响， 结果检验了长江一洞庭湖流量关系变化对长江中 游河道演变趋势影响,很好地预测了 2000-2015 年 荆江弯曲河道及城陵矶一汉口段江心洲分汉河道 的演变趋势。

在这个过程中, 申请批准并完成了“大坝上、下 河道演变趋势实验研究”(1986-1988 年,No.852989, 地 65055)(金德生, 1986; 金德生等, 1992); “流水地 貌系统演化过程实验研究” (1990-1992 年, No.48870008)(Jin et al, 1986; 金德生, 1990) 以及“流 水地貌系统突变过程实验研究”(1993-1996 年, No.49271013)(金德生, 1995)等国家自然科学面上 基金项目。1992-1994 年,在内蒙赤峰市翁牛特旗 建立隋家窝铺小流域综合实验场,进行小流域侵蚀 产沙综合实验观测,完成中国科学院“八五”科技扶 贫项目“承德赤峰贫困山区开发治理与试验研究” (金德生等, 1996)。1988-1989年,配合清华大学水 利系泥沙实验室博士研究生倪晋仁撰写博士论文 《不同边界条件下河型成因的试验研究》,完成二元 相结构中分汉河道成因演变过程响应模型实验(倪 晋仁, 1993);1993 年配合北京大学环境工程研究所 徐为群撰写硕士论文《黄土坡面侵蚀过程实验研 究》, 进行黄土坡面侵蚀过程的过程响应模型实验 (徐为群等, 1995a; 徐为群等, 1995b)。

\section{2 开拓流域地貌系统及坡面发育演变的实验}

河流地貌实验由河床发育演变向流域水系及 
坡面演变发育发展。通过室内人工降雨条件下的 模型试验研究了水系的发育过程, 发现产沙过程具 有波动振荡衰减特征, 水系分数维值随时间呈不对 称上凹型曲线; 在水系发育过程中有 2 种最小消能 方式: (1)河道(沟道)数目增加; (2)沟道拉伸弯曲(金 德生, 陈浩等, 2000)。在流域水系发育过程中, 由 于侵蚀基面的下降, 相应地促使增大流域势能, 产 沙具有复杂响应过程。在时间上,先后两次基面下 降带来的影响各不相同, 后一次比前一次带来的影 响较弱, 消能率变小; 在空间上, 有河口溯源而上, 其影响越来越弱, 其影响的空间范围也越来越小 (金德生等, 1995; Jin et al, 1997; Zhang et al, 1999; 金德生等, 2003)。

坡面产流产沙及坡面形态发育过程实验表明: 当不考虑地质构造运动影响时, 黄土坡面的产流、 产沙量开始时迅速增大, 随后缓慢增加, 最后达到 平衡。具体表现为: 降雨人渗过程遵循 Horton 的均 匀人渗规律; 产流过程遵循随时间递增趋向稳定的 规律; 产沙过程显得比较复杂, 但总体趋势与产流 过程类似, 不同发育阶段所产泥沙的级配差异不大 (徐为群等, 1995a)。坡面发育实验揭示了当过程趋 于稳态时黄土坡面的侵蚀过程, 主要经历分别以面 蚀与细沟侵蚀, 细沟和浅沟侵蚀, 浅沟和细沟侵蚀 为主, 但侵蚀量相对稳定的 3 个发育阶段。这与自 然界中黄土地貌源、梁或峁中、上部的一个完整发 育过程十分相类似, 经历幼年期、中年期及最后的 老年期, 坡面形态与侵蚀状况趋向平衡; 在坡面侵 蚀过程中,具有面蚀和沟蚀 2 种不同的侵蚀机理。 面蚀量与沟蚀量的变化过程迥然不同, 前者初始时 有最大值, 渐次减小, 趋于稳定; 而后者的趋势则相 反, 当沟道缓慢变得成熟时, 沟蚀量比较稳定, 这时 河网格局也基本趋向稳定, 2 种侵蚀同时并存, 侵蚀 量也相当稳定, 不过沟蚀量一般大于面蚀量。另 外, 凸型纵剖面与细沟初始发育阶段相伴而生, 随 后渐次转向直型、折线型纵剖面, 最后演变成上凸 下凹型纵剖面, 与平衡状态相对应, 当然这是侵蚀 基准面稳定条件下的情况(徐为群等, 1995b)。

\section{3 建立河流地貌过程响应实验相似性理论}

自 1967 年以来, 近半个世纪的实验研究表明, 河流地貌模拟实验的相似,应遵循以牛顿力学为基 础的几何相似、运动相似及动力相似, 原模型中的 相似准数相近或相等。由于影响地貌过程的因素
诸多而复杂, 加之地貌过程的多变及多样性, 地貌 过程模似应遵循“第四相似准则”(Hooke, 1968), 即 地貌作用行为的相似,并进而推广到第五相似准则 “地貌型相似”, 即 : (1)地貌形态统计特征; (2)物质组 成比例与层次结构比例; (3)相对时间尺度及相对速 率; (4)因果关系; (5)消能率及消能方式等等方面的 相应或相似(金德生, 1990)。这种“地貌型相似”适 用于 “河型相似”, 即以河型分类及成因分析为前 提, 借助比降一流量临界关系, 河谷比降一曲率临 界关系, 曲率一河岸结构比临界关系等设计模型, 塑造各种相似性河型, 如弯曲、分汉、游荡及网状等 河型。同时,将该理论推广到“坡地地貌型相似”, “流域地貌型相似”,以及“流水地貌系统相似”等一 系列地貌与第四纪沉积问题相似(金德生, 1990, 1995)。在运用“异构同功”原理和空代时假定进行 地貌类比性分析及地貌过程的计算机模拟时, 起到 重要作用。

\section{4 河流地貌实验的新进展}

20 世纪60-70年代,沈先生十分注重现代地理 学及现代地貌学的实验研究, 基于这一指导思想, 自 90 年代中期以来的 20 多年中, 河流地貌的实验 设备得到更新发展,进行了有关流域地貌系统、坡 面发育、冲积河流河型成因的室内模拟实验,并进 行了控制流水地貌系统发育因素,诸如基面变化、 隆升沉降、物质组成及植被对流水地貌系统发育影 响的实验研究。

\section{1 河流地貌实验室建设及实验装置更新}

实验设备及实验仪器的的更新将极大地促进 实验成果的获得。成果包括: (1)实验设备的结构由 单一型向复合型发展; (2)实验驱动由手动型向半自 动型、全自动型发展; (3)实验功能由简单型向复杂 型发展; (4)实验数据与图像获取的手段日益先进、 内容愈益丰富。

20 世纪 90 年代, 长江大学(原江汉石油学院)湖 盆沉积模拟实验室, 引进流水地貌实验室升降装置 的设计理念, 结合油气勘探及储存的需求, 研制完 成了类似的地壳升降模拟装置。该装置是由 4 块 $2.5 \mathrm{~m} \times 2.5 \mathrm{~m}$ 块钢板组合而成, 上覆胶皮,整体面积 $5 \mathrm{~m} \times 5 \mathrm{~m}$, 由 16 个液压千斤顶蜗杆支撑, 蜗杆与钢 板间呈球状连接, 以及一套升降控制系统组成, 附 
有一套蜗轮蜗杆箱及相关控制系统。利用该装置 着重研究构造变形对河道河口及湖盆成因演变的 影响, 石油生成与石油储存层的分布规律, 研究陆 相成油率理论。该实验室的赖志云、张春生等结合 实地考察, 运用类似的升降装置成功模拟了有关人 湖盆河流三角洲沉积过程、沉积结构以及河道演 变、河流沉积方面的实验成果(赖志云等, 1994; 张 春生等, 1997; 赖志云等, 2006)。

21 世纪初, 由于 2008 年第 29 届奥运会的需要, 原中科院地理研究所流水地貌实验室迁址, 在中国 科学院地理科学与资源研究所水土实验室中, 重建 长 $40 \mathrm{~m} \times 6 \mathrm{~m}$ 的河流地貌实验槽, 由 20 世纪 70 年代 的半自动控制的升降装置, 吸取长江大学自动控制 升降装置的优点, 于 2014 年建成自动智能控制的高 精度地壳升降运动复杂模拟系统, 并进行调试和 运行。

该模拟系统由 12 块钢板组合而成, 胶皮整体面 积 $10 \mathrm{~m} \times 8 \mathrm{~m}$; 每块钢板 $2.95 \mathrm{~m} \times 2.95 \mathrm{~m}$, 蜗杆支撑, 蜗杆与钢板呈球状连接, 12 套蜗轮蜗杆箱套及相关 控制系统; 可以模拟多种形式的复杂构造变形, 及 其对流域、河道、河口演变的影响, 以及对流域地下 含水层变形及地下水循环影响。该系统的构造变 形的速率为: $0.01 \sim 0.02 \mathrm{~mm} / \mathrm{s}$; 构造变形幅度: 单一 升降幅度 $+30 \mathrm{~cm}$, 断块差别升降幅度为 $60 \mathrm{~cm}$, 纵向 与横向掀斜幅度 $+30 \mathrm{~cm}$; 褶皱尧曲顶部与凹部最大 幅度为 $50 \mathrm{~cm}$, 穹隆中心上升幅度与凹陷中心下降 幅度分别为 $+30 \mathrm{~cm}$ 与 $-30 \mathrm{~cm}$; 升降精度: $+0.1 \mathrm{~mm}$, 穹隆周边上升幅度与凹陷周边下降幅度均为 +0.1 $\mathrm{mm}$, 可通过单独运行的各个蜗轮蜗杆箱套, 由软件 同步协调自动控制软件, 进行异步和同步、逐级和 无级操作。至少可以模拟 4 大类 80 多种垂直升降 运动。各种构造变形能给出变形过程的可视化演 示 ${ }^{\circledR}$ 。完成了国家自然科学基金学部主任基金项目 “冲积河流对隆起与坳陷非均匀活动响应的实验研 究”(No.41340021)(金德生等, 2015)。

\section{2 河型系统发育演变过程实验的新进展}

在弯曲河型及分汉河型发育实验研究的基础 上, 成功地模拟游荡河型及网状河型的发育演变, 并进一步对河流发育的突变过程及复杂响应进行 验证实验。

游荡型模型小河过程响应模型实验过程中所
揭示的时、空演变过程, 说明空代时假说的客观存 在性,为该假说提供新证据,同时可以划分出 2 类复 杂响应过程：(1)时间复杂响应过程,某一特定空间 各要素随时间的变化过程; (2)空间复杂响应过程。 某一特定时间各要素随地域空间的变化过程,两者 可以相互替代。不过, 要是忽视了对象的时空尺 度、主要控制方式及控制变量,必然会得出错误的 结论(张欧阳等, 2000)。地貌分析中,借助空间变量 代替时间变量建立严格的数学模型是不一定恰当 的(Craig, 1982)。空代时假说的优点是, 可以粗略 地用地貌发育的空间过程预测时间过程, 反过来, 用时间过程来预测空间过程;两者可以分别为工程 建设、减灾,以及为规划部门提供参考依据(张欧阳 等, 2000)。

实验分析表明,复杂响应普遍存在于江心洲分 汉河型及游荡河型的发育过程中, 当江心洲河型受 到一次侵蚀基面下降影响时, 出现新老江心洲套叠 现象，而游荡河型表现为时间复杂响应和空间复杂 响应。通过实验,验证模型小河发育过程中,其纵 剖面明显存在非线性分形特征(金德生等, 1997)。

王随继等(2004)关于网状河流多重河道形成过 程的模拟实验结果, 与金德生等(1985)在江心洲分 汉发育过程模拟实验获得的结果相当接近。但是, 江心洲形成过程有所不同: 在网状河道发育过程中 泛滥平原的结构一上层高岭土和下层细砂始终保 留着,沉积层不遭受扰动。所塑造成的河流体系具 有多股河道, 将泛滥平原切割成长条形江心洲, 连 同泛滥平原都十分稳定，与自然界的网状河流非常 相似; 而后者是河道侧向摆动时,通过侧向加积所 之, 随着河道进一步摆动, 这些江心洲往往被新汉 河所侧蚀,侧向迁移十分显著,往往从一边摆到另 一边, 摆幅竟然达 3 4 m。正如有学者指出的那样, 网状河流的发育是河漫滩上的河道化过程, 而分汉 河流的形成是河道内部的江心洲化过程(王随继等, 2000; 王随继, 2002)。

\section{3 穹隆与坳陷非均匀升降对河流地貌系统发育影 响的实验}

2014年,实验室申请获准国家自然科学基金委 地球科学部主任基金项目“冲积河流对隆起与坳陷 非均匀活动响应的实验研究”(No.41340021)。以黄 河下游游荡一弯曲性过度型河段为背景, 完成了弯

(1)笔者已根据相关实验数据对各种构造变形进行了变形过程的可视化演示。 
曲一游荡性过渡型河道造床、穹隆抬升及坳陷沉降 对弯曲一游荡性过渡型河道发育影响等 3 大组 10 个测次的实验。

\subsection{1 弯曲一游荡性过渡型河道造床实验}

游荡一弯曲型模型小河造床实验共进行 5 个测 次。在实验过程中, 由于边界条件相对疏松, 而且 在不很典型的二元相结构河漫滩中发育, 在放水总 历时 $98.5 \mathrm{~h}$ 后, 已经成功塑造成弯曲一游荡过渡型 过渡河段。在断面 1-7 $7^{*}$, 比较顺直, 断面 7-13 $3^{*}$ 顺直 微弯, 凸岸边滩具有切滩发育江心洲的态势; 断面 13-19" 比较弯曲, 发育较完整的凸岸边滩; 断面 $19^{*}$ 以下首先微弯, 进而弯曲, 并经历弯曲河道主流左 右摆动的发育过程。

在发育过程中, 边滩的发育过程为: 首先在凸 岸水下形成潜边滩, 进而出露水面成维形边滩, 边 滩的长宽比较小, 大约为 3:1 4:1; 随着河道曲率的 增大, 边滩的长宽比缩小为 $2: 1 \sim 1.5: 1$ 。此时, 发生 边滩切割形成江心洲。

这次造床实验之所以进展较快, 主要是由于河 道边界物质比较疏松, 河漫滩结构尽管按照二元相 结构铺设, 但不是很典型。以断面 $13^{\#}$ 为界, 断面 $13^{\#}$ 上游的河漫滩相粉土与粉砂比为 $1: 7$, 相对更加疏 松; 断面 $13^{*}$ 以下的河漫滩相, 粉土与粉砂比对半, 相对比较粘实。水力几何形态分析表明: 当放水 $98.5 \mathrm{~h}$ 后, 实验已造成弯曲一游荡过性型模型小河。

4.3.2 穹隆抬升对弯曲游荡性过渡型河道发育影响 实验

抬升实验是在上述弯曲一游荡过性型模型小 河实验基础上进行的, 目的是检验局部河段在受穹 隆缓慢上升时作出的响应。其中快速上升速率 $10.0 \mathrm{~mm} / \mathrm{h}$, 中速上升速率 $6.67 \mathrm{~mm} / \mathrm{h}$, 慢速上升速率 $3.33 \mathrm{~mm} / \mathrm{h}$, 平均上升速率为 $0.10 \mathrm{~mm} / \mathrm{min}$, 上升总 幅度为 $100 \mathrm{~mm}$, 总历时 $16 \mathrm{~h}$, 由程序自动控制。4 个抬升装置按“十”字型构成, 在水槽中, 位在 13-17" 断面下方, 抬升装置顶面为 0 位, “十”字的横线位在 $15^{\#}$ 断面上，“十”字的坚线位在初始模型小河的中心 线上, 这样设置是便于河道左右侧受构造活动影响 的对比。

不同速率隆升实验表明, 在隆升区及其上下游 河段, 模型冲积河流都显示出不同程度的响应。如 果分别以河床演变速率及河流地貌上升幅度表示 响应的敏感性及强度, 那么河道对慢速抬升、中速
抬升到快速抬升作出的响应, 敏感性不断增强, 演 变速率增大; 河道侵蚀速率增大, 相应地河流阶地 发育的速度与相对高度及曲流刷深的程度不断 递增。

4.3.3 坳陷沉降对弯曲一游荡性过渡型河道发育影 响实验

坳陷沉降实验是在上述实验基础上,将模型小 河调平到零位, 并进行必要的放水实验, 而后进行 3 种速率的沉降实验, 目的是检验局部河段在受坳陷 缓慢沉降时作出的响应。沉降实验总历时 $16 \mathrm{~h}$, 沉降 总幅度-160 mm, 慢速沉降速率-6.67 mm/h, 中速沉 降速率 $-10.0 \mathrm{~mm} / \mathrm{h}$, 快速沉降速率 $-20 \mathrm{~mm} / \mathrm{h}$, 平均沉 降速率为 $-0.17 \mathrm{~mm} / \mathrm{min}$, 由程序自动控制沉降运 动, 同样在上述 4 个按“十”字型构成的升降装置中 实现。不同速率沉降实验表明,在沉降区本身及其 上下游河段,模型冲积河流都显示出不同程度的响 应。如果用变化速率来表示敏感性,河道对慢速沉 降、中速沉降到快速沉降作出的响应, 敏感性不断 增强, 演变速率增大 ; 侵蚀及沉积速率增大, 相应 地, 在沉降区形成的水下三角洲发育速度与规模, 以及汉河刷深的程度不断递增。

\section{5 结语与展望}

沈先生逝世 20 多年来, 在我们缅怀沈先生流水 地貌实验思想的初衷之际, 深深感到, 沿着沈先生 的思路, 流水地貌实验室的建设、扩展与重建, 实验 理论方法的建立与创新, 流域系统、坡面发育、河道 成因、河型演化、内外营力作用以及宏微观边界条 件影响的实验研究等, 均取得了一系列进展。为了 使我国实验流水地貌学研究继续深化, 需要进行以 下方面开拓性创新探索:

（1）加强河流地貌系统对新构造运动、气候变 化与人类活动响应，以其相互间的模拟实验研究。

（2）加强构造运动、气候变化及人类活动快速 变化导致的非稳定状态河流动力地貌过程实验研 究,揭示其复杂性、敏感性及前兆性特征。

(3) 开展河流地貌系统中以水为载体的多元物 质(泥沙、污染物、生源要素)迁移过程及其生态效应 的实验研究。

(4) 结合河流地貌学中若干难题的进一步破 解, 如河型的成因、突变与模拟(如弯曲河型的成因 
与模拟)、河相关系方程组的封闭求解等, 进行一些 流水地貌的基础实验研究。

(5) 抓住模型实验与数学模拟研究之间的发展 空间: 物理实体模拟实验具有确定数学模拟求解的 边界条件优势, 而数学模拟具有易设定参数缩短过 程模拟时间的优势; 但是物理模型实验费时费力, 数学模拟不容易获得实体效果。因此, 两者不可替 代, 应取长补短, 促进优势互补, 加强相互融合, 将 物理模型实验与数学模拟实验融为一体, 乃至朝新 的方向发展, 与原型实测数据联机, 进行三者结合 为一体的流水地貌实时实验。

（6）加强有关科研机构、高等院校和生产部门 中相当可观的中青年实验研究力量的协作与融合, 加强流水地貌实验研究的综合性、交叉性学术交 流; 20 世纪 90 年代, 在中国地理学会地貌与第四纪 地质专业委员会的支持下, 1993 年在无锡召开了 “第一届地貌实验与模拟研讨会”, 会上正式宣布成 立 “地貌实验与模拟组”, 总结交流了有关分支地貌 学科的室、内外实验模拟成果, 促进了该方面研究 的进一步发展(金德生, 1993)。通过有关组织,例 如, 中国地理学会, 向国家自然科学基金委建议设 立更多专项基金,促进研究的深化和细化等。我们 相信, 流水地貌实验研究必将步人一个崭新的发展 阶段。

\section{参考文献(References)}

蔡强国. 1982. 地壳构造运动对河型转化影响的实验研究 [J]. 地理研究, 1(3): 21-32. [Cai Q G. 1982. An experimental study of river pattern changes influenced by tectonic movement[J]. Geographical Research, 1(3): 21-32.]

洪笑天, 马绍嘉, 郭庆伍. 1987. 弯曲河流形成条件的实验研 究 [J]. 地理科学, 7(1): 35-43. [Hong X T, Ma S J, Guo Q W. 1987. An experimental study on the forming conditions of meandering rivers[J]. Scientia Geographica Sinica, 7(1): 35-43.]

金德生. 1986. 边界条件对曲流发育影响的过程响应模型实 验研究[J]. 地理研究, 5(3): 12-21. [Jin D S. 1986. An experimental study of the influence of boundary conditions on meandering development with process response model [J]. Geographical Research, 5(3): 12-21.]

金德生. 1990. 河流地貌系统的过程响应模型实验 $[\mathrm{J}]$. 地理 研究, 9(2): 20-28. [Jin D S. 1990. A process-response modelling in the river morphological system[J]. Geographical
Research, 9(2): 20-28.]

金德生. 1993. 全国第一届地貌实验与模拟研讨会在无锡市 召开[J]. 地理学报, 48(5): 479-480. [Jin D S. 1993. Quanguo diyijie dimao shiyan yu moni yantaohui zai Wuxishi zhaokai[J]. Acta Geographica Sinica, 48(5): 479-480.]

金德生. 1995. 地貌过程实验模拟研究若干问题 $[M] / /$ 中国地 理学会地貌与第四纪专业委员会编. 《地貌过程与环境》 文集. 北京: 地震出版社: 289-295. [Jin D S. 1995. Dimao guocheng shiyan moni yanjiu ruogan wenti[M]//Zhongguo Dilixuehui Dimao Yu Disiji Zhuanye Weiyuanhui bian. "Dimao guocheng yu huanjing" wenji. Beijing, China: Seismological Press: 289-295.]

金德生. 1997. 下游河流纵剖面特征与演变 $[\mathrm{M}] / /$ 叶青超, 尤 联元, 许昫心, 等. 黄河下游地上河发展趋势与环境后 效. 郑州: 黄河水利出版社: 84-95. [Jin D S. 1997. Xiayou heliu zongpoumian tezheng yu yanbian[M]//Ye Q C, You L Y, Xu J X, et al. Huanghe xiayou dishanghe fazhan qushi yu huanjing houxiao. Zhengzhou, China: Yellow River Water Conservancy Press: 84-95.]

金德生, 等. 1996. 隋家窝铺小流域水资源开发利用及其农 业生态效益分析 $[\mathrm{M}] / /$ 康庆禹, 朱景郊, 王旭. 承德、赤峰 地区科技扶贫开发研究. 北京: 中国农业科技出版社: 151- 163. [Jin D S, et al. 1996. Suijiawopu xiaoliuyu shuiziyuan kaifa liyong jiqi nongye shengtai xiaoyi fenxi [M]//Kang Q Y, Zhu J J, Wang X. Chengde, Chifeng diqu keji fupin kaifa yanjiu. Beijing, China: China Agricultural Science and Technology Press: 151-163.]

金德生, 陈浩, 郭庆伍. 1997. 河道纵剖面分形一非线性形态 特征 [J]. 地理学报, 52(2): 154-162. [Jin D S, Chen H, Guo Q W. 1997. A perelminary study on non-linear properties of channel longitudinal profiles[J]. Acta Geographica Sinica, 52(2): 154-162.]

金德生, 陈浩, 郭庆伍. 2000. 流域物质与水系及产沙间非线 性关系实验研究 [J]. 地理学报, 55(4): 439-448. [Jin D S, Chen H, Guo Q W. 2000. An experimental study on influence of materiel component to non-linear relation between sediment yield and drainage network development[J]. Acta Geographica Sinica, 55(4): 439-448.].

金德生, 陈浩, 张欧阳, 等. 2003. 侵蚀基准面下降对水系发 育与产沙间非线性关系影响的实验研究 $[\mathrm{J}]$. 地理研究, 22(5): 560-570. [Jin D S, Chen H, Zhang O Y, et al. 2003. Influence of base level lowering on sediment yield and drainage network development: An experimental analysis [J]. Geographical Research, 22(5): 560-570.] 金德生, 郭庆伍. 1995. 均质流域地貌发育过程实验研究 
$[\mathrm{M}] / /$ 金德生. 地貌实验与模拟. 北京: 地震出版社: 79101. [Jin D S, Guo Q W. 1995. Junzhi liuyu dimao fayu guocheng shiyan yanjiu[M]//Jin D S. Dimao shiyan yu moni. Beijing, China: Seismological Press: 79-101.]

金德生, 郭庆伍, 马绍嘉, 等. 1991. 长江下游马鞍山河段演 变趋势试验研究 $[M] / /$ 中国地理学会地貌与第四纪专业 委员会. 地貌及第四纪研究进展. 北京: 测绘出版社: 106113. [Jin D S, Guo Q W, Ma S J, et al. 1991. Changjiang xiayou Maanshan heduan yanbian qushi shiyan yanjiu[M]// zhongguo Dilixuehui Dimao Yu Disiji Zhuanye Weiyuanhui. Dimao ji disiji yanjiu jinzhan. Beijing, China: Surveying and Mapping Press: 106-113.]

金德生, 洪笑天. 1985. 分汉河型的实验研究 $[\mathrm{M}] / /$ 中国科学 院地理研究所, 等. 长江中下游河道特性及其演变. 北 京: 科学出版社: 214-254. [Jin D S, Hong X T. 1985. Fencha hexing de shiyan yanjiu[M]//Institute of Geography, CAS, et al. Changjiang zhongxiayou hedao texing jiqi yanbian. Beijing, China: Science Press: 214-254.]

金德生, 刘书楼, 郭庆伍. 1992. 应用河流地貌实验与模拟研 究 [M]. 北京: 地震出版社. [Jin D S, Liu S L, Guo Q W. 1992. Yingyong heliu dimao shiyan yu moni yanjiu[M]. Beijing, China: Seismological Press.]

金德生, 乔云峰, 杨丽虎, 等. 2015. 新构造运动对冲积河流影 响研究的回顾与展望 [J]. 地理研究, 34(3): 437-454. [Jin D

S, Qiao Y F, Yang L H, et al. 2015. A research of influence of neo-tectonic movement on alluvial rivers: Review and prospect[J]. Geographical Research, 34(3): 437-454.]

金德生, 张欧阳, 陈浩, 等. 2000. 小浪底水库运用后黄河下 游游荡性河段深泓演变趋势分析 [J]. 泥沙研究, (6): 5262. [Jin D S, Zhang O Y, Chen H, et al. 2000. Analysis of Thalweg evolution tendency of the wandering reach in the Lower Yellow R. after Xiaolangdi Reservoir operation[J]. Journal of Sediment Research, (6): 52-62.]

赖志云, 赖伟庆, 刘震, 等. 2006. 湖盆模拟实验沉积学 $[M]$. 北京: 石油工业出版社: 175. [Lai Z Y, Lai W Q, Liu Z, et al. 2006. Hupen moni shiyan chenjixue[M]. Beijing, China: Petroleum Industry Press: 175.]

赖志云, 周维. 1994. 舌状三角洲和鸟足状三角洲形成及演 变的沉积模拟实验 [J]. 沉积学报, 12(2): 37-44. [Lai Z Y, Zhou W. 1994. Experimental formation and development of Lobate and Birdfoot deltas[J]. Acta Sedimentologica Sinica, 12(2): 37-44.]

李保如. 1963. 自然河工模型试验 $[\mathrm{M}] / /$ 水利水电科学研究院

科学研究论文集, 第 2 集(水文、河渠). 北京: 中国工业出
版社: 111. [Li B R. 1963. Ziran hegong moxing shiyan [M]//Shuili Shuidian Kexue Yanjiuyuan kexue yanjiu lunwenji, dierji(shuiwen, hequ). Beijing, China: Chinese Industry Press: 111.]

罗海超, 周学文, 尤联元, 等. 1980. 长江中下游分汉河道成 因研究 $[\mathrm{M}] / /$ 第一届国际河流泥沙讨论会论文集. 北京: 光华出版社: 437-446. [Luo H C, Zhou X W, You L Y, et al. 1980. Study on the causes of river branch points in the middle and Lower Yangtze River[M]//The first international symposium on river sediment. Beijing, China: Guanghua Press: 437-446.]

罗辛斯基 К И, 库兹明И А. 1956. 河床 $[\mathrm{J}]$. 谢鉴衡, 译. 泥沙 研究, 1(1): 115-151. [Росинский К И, Кузъмин И А. 1956. Hechuang[J]. Xie J H, Trans.. Journal of Sediment Research, 1(1): 115-151.]

马卡维耶夫, 赫米列娃, 扎依托夫, 等. 1966. 实验地貌学 [M]. 誉静娟, 陆中臣, 杨毅芬, 等, 译. 北京: 科学出版社: 156. [Маккавеев Н И, Хмелева Н В, Заитов И Р, et al. 1966. Shiyan dimaoxue[M]. Pu J J, Lu Z C, Yang Y F, et al Trans.. Beijing, China: Science Press: 156.]

倪晋仁. 1993. 不同边界条件下河型成因的试验研究 $[M] / /$ 年 报编辑组.《清华大学核能技术设计研究院年报 1992 年》, 博士学位论文摘要汇编. 北京: 清华大学出版社: 144. [Ni J R. 1993. Butong bianjie tiaojianxia hexing chengyin de shiyan yanjiu[M]//Nianbao bianjizu. "Qinghua Daxue Heneng Jishu Sheji Yanjiuyuan nianbao, 1992", boshi xuewei lunwen zhaiyao huibian. Beijing, China: Tsinghua University Press: 144.]

沈玉昌. 1965. 长江上游河谷地貌 $[\mathrm{M}]$. 北京: 科学出版社: 103. [Shen Y C. 1965. Changjiang shangyou hegu dimao [M]. Beijing, China: Science Press: 103.]

唐日长. 1964. 蜿蜓性河段成因的初步分析和造床实验研究 [J]. 人民长江, (2): 13-21. [Tang R Z. 1964. Wanyanxing heduan chengyin de chubu fenxi he zaochuang shiyan yanjiu[J]. Yangtze River, (2): 13-21.]

王随继. 2002. 两类多河道河流的形成模式及河道稳定性比 较 [J]. 地球学报, 23(1): 89-93. [Wang S J. 2002. Comparison of formation model and channel stability between two different sorts of multiple channel river patterns[J]. Acta Geosicientia Sinica, 23(1): 89-93.]

王随继, 薄俊丽. 2004. 网状河流多重河道形成过程的实验 模拟 [J]. 地理科学进展, 23(3): 34-42. [Wang S J, Bo J L. 2004. Experimental simulation of anastomosing multiple channel formation[J]. Progress in Geography, 23(3): 34-42.] 
王随继, 尹寿鹏. 2000. 网状河流和分汉河流的河型归属讨 论 [J]. 地学前缘, 7(S1): 79-86. [Wang S J, Yin S P. 2000. Discussion on channel patterns of anastomosing and anabranched rivers $[\mathrm{J}]$. Earth Science Frontiers, 7(S1): 7986.]

许昫心. 1983. 边界条件对水库下游河床演变的影响: 以汉 江丹江口水库下游河道为例 [J]. 地理研究, 2(4): 60-71. [Xu J X. 1983. The effect of boundary conditions upon the channel process downstream the Dan-Jiang-Kou Reservoir [J]. Geographical Research, 2(4): 60-71.]

徐为群, 倪晋仁, 徐海鹏, 等. 1995a. 黄土面坡侵蚀过程实验 研究: I. 产流产沙过程[J]. 水土保持学报 9(3): 9-18, 77. [Xu W Q, Ni J R, Xu H P, et al. 1995a. Experimental study on erosion process over loess slopes: I. Surface flow and sediment transport[J]. Journal of Soil and Water Conservation, 1995, 9(3): 9-18, 77.]

徐为群, 倪晋仁, 徐海鹏, 等. 1995b. 黄土坡面侵蚀过程实验 研究: II. 坡面形态过程 [J]. 水土保持学报, 9(4): 19-28. [Xu W Q, Ni J R, Xu H P, et al. 1995b. Experimental study on erosion process over loess slopes: II. Surface flow and sediment transport[J]. Journal of Soil and Water Conservation, 9(4): 19-28.]

尹学良. 1965. 弯曲性河流形成原因及造床试验初步研究 [J]. 地理学报, 31(4): 287-303. [Yin X L. 1965. Wanquxing heliu xingcheng yuanyin ji zaochuang shiyan chubu yanjiu[J]. Acta Geographica Sinica, 31(4): 287-303.]

尤联元, 金德生, 陈浩, 等. 1987. 三峡工程修建后下游河道 变化预估, (四)过程响应实验研究 $[\mathrm{M}] / /$ 中国科学院三峡 工程生态与环境科研项目领导小组. 长江三峡工程对生 态与环境影响及其对策研究论文集. 北京: 科学出版社: 260-276. [You L Y, Jin D S, Chen H, et al. 1987. Sanxia gongcheng xiujianhou xiayou hedao bianhua yugu, (si)guocheng xiangying shiyan yanjiu[M]//Zhongguokexueyuan Sanxia Gongcheng Shengtai Yu Huanjing Keyan Xiangmu Lingdao Xiaozu. Changjiang Sanxia gongzuo dui shengtai yu huanjing yingxiang jiqi duice yanjiu lunwenji. Beijing, China: Science Press: 260-276.]

张春生, 刘忠保. 1997. 现代河湖沉积与模拟实验 $[\mathrm{M}]$. 北京: 地质出版社: 261. [Zhang C S, Liu Z B. 1997. Xiandai hehu chenji yu moni shiyan[M]. Beijing, China: Geological Publishing House: 261.]

张欧阳, 金德生, 陈浩. 2000. 游荡河型造床实验过程中河型 的时空演替和复杂响应现象 [J]. 地理研究, 19(2): 180188. [Zhang O Y, Jin D S, Chen H. 2000. An experimental study on spatial and temporal processes and complex response of river channel evolution[J]. Geographical Research, 19(2): 180-188.]

中国科学院地理所地貌室. 1981. 长江中、下游鹅头状河型 的成因与演变规律的初步探讨: 以官洲河段为例 $[\mathrm{M}] / /$ 中 国地理学会地貌与第四纪专业委员会. 中国地理学会 1977 年地貌学术讨论会文集. 北京: 科学出版社: 30-41. [Zhongguo Kexueyuan Dilisuo Dimaoshi. 1981. Changjiang zhongxiayou etouzhuang hexing de chengyin yu yanbian gulv de chubu tantao: Yi Guanzhou heduan weili[M]// Zhongguo Dilixuehui Dimao Yu Disiji Zhuanye Weiyuanhui. Zhongguo Dilixuehui 1977nian dimao xueshu taolunhuiwenji. Beijing, China: Science Press: 30-41.]

中国科学院地理研究所地貌研究室, 长江模型实验小组. 1978. 长江中、下游分汉河道演变的实验研究 [J]. 地理学 报, 32(2): 128-141. [The Experimental Group of the Yangtze Model, Division of Geomorphology, Institute of Geography, Academia Sinica. 1978. An experimental study on the fluvial processes of the braided stream in the middle and lower reaches of the Yangtze River[J]. Acta Geographica Sinica, 32(2): 128-141.]

Craig R G. 1982. The ergodic principle in erosional models $[\mathrm{M}] / /$ Thorn C E. Space and time in geomorphology. Landon, UK: George Allen and Unwin: 379.

Friedkin J F. 1945. A laboratory study of the meandering of alluvial rivers[R]. Vicksburg, MS: U.S. Waterways Experiment Station.

Hooke R L. 1968. Model geology: Prototype and laboratory streams: Discussion[J]. Geological Society of America Bulletin, 79(3): 391-394.

Jin D S, Chen H, Zhang O Y. 1997. An experimental study on bedmaking and catastrophic processes in island braided channel[J]. International Journal of Sediment Research, 12 (3): 225-239.

Jin D S, Schumm S A. 1986. A new technique for modelling river morphology[C]/Richards K S. Proceedings of the first international conference on geomorphology. Chichester, UK: Wiley: 681-690.

Zhang O Y, Jin D S, Chen H. 1999. An experimental study on temporal and spatial processes of wandering-braided river channel evolution[J]. International Journal of Sediment Research, 14(2): 31-38.

Великанов М А. 1950. Моделирование руслвого процесса [Ј]. ДАН СССР, 74(3). 


\title{
Development and innovation of fluvial geomorphological experiments:
}

\section{To mark contributions of Professor Shen Yuchang on the hundredth anniversary of his birth}

\author{
JIN Desheng, QIAO Yunfeng* \\ (Key Laboratory of Water Cycle and Land Surface Processes, Institute of Geographic Sciences and Natural \\ Resources Research, CAS, Beijing 100101, China)
}

\begin{abstract}
Professor Shen Yuchang, as a pioneer and founder of modern river geomorphology research in China and his original idea created a new era of experimental research of fluvial geomorphology. The author wrote this article to celebrate the 100th anniversary of the birth of Professor Shen. The article introduces the following developments: (1) A vision for river geomorphological experiments and preparing for building the fluvial geomorphic laboratory, including Prof. Shen's original idea, research and preparation for the laboratory, test operation and starting experiments. (2) Expansion of the fluvial geomorphological laboratory and booming experimental research, including a series of experimental research ranging from major national research projects and local projects, pioneering experimental research on the evolution of watershed geomorphic systems and slope systems, and establishing the process-response similarity theory for fluvial geomorphological experiments. (3) Recent progress in river geomorphological experiments, including the development of the river geomorphological laboratory and updating lab equipment, phylogenetic evolution experiment of channel patterns, and river geomorphic system's response to dome and depression of non-uniform uplift and subsidence, among others. (4) Finally, the article points out that in order to advance the study on fluvial geomorphological experiments in China, it is needed to continue innovations in six areas, including strengthen the experiments on non- steady state river geomorphological process caused by tectonic movement, climate change, and rapidly changing human activities to reveal the complexity, sensitivity, and precursory characteristics; and strengthen collaboration and integration of experimental research forces to enhance comprehensiveness of research and cross fertilization.
\end{abstract}

Key words: celebrating the original idea; river geomorphology; experiment; innovation and development 